\title{
Anterior Segment Optical Coherence Tomography in Monitoring Therapeutic Response in Viral Disciform Keratitis
}

\section{Vijay KS* and Sagarika P \\ Army hospital, Research and Referral, India}

Corresponding author: Vijay K Sharma, Consultant, Ophthalmology, Army Hospital Research and Referral, Delhi Cantt- 110010, India, Tel: 091-8826956710; Email: vijayshrma007@gmail.com

\section{Research Article}

Volume 3 Issue 4

Received Date: June 11, 2018

Published Date: July 06, 2018

\section{Abstract}

Purpose: To describe the characteristic anterior segment optical coherence tomography (ASOCT) features and its role in monitoring therapeutic response in viral disciform keratitis.

Methods: A retrospective analysis of records of four eyes of four patients of viral disciform keratitis was performed. The responses to therapy by tablet Acyclovir $400 \mathrm{mg}$ five times a day and topical steroid was monitored by serial ASOCT at each visit.

Results: All patients showed marked improvement in visual acuity and ASOCT characteristics after starting treatment. The site of maximum corneal thickness was outlined by ASOCT and evaluated on serial ASOCT. Corneal thickness showed maximum reduction in initial two weeks period with resolution in stromal oedema and smoothening of posterior corneal contour. Hyperreflectivity on ASOCT showed initial increase after resolution of stromal oedema followed by decrease over next two months period.

Conclusion: ASOCT evaluation of cornea may provide an important surrogate objective measure for assessment of viral disciform keratitis and monitoring the response to treatment.

Keywords: ASOCT; Disciform Keratitis; Stromal Oedema

\section{Introduction}

Anterior segment optical coherence tomography (ASOCT) has become a very important tool in diagnosis, evaluation and management of corneal diseases. It has been used successfully in evaluation of microbial keratitis, corneal ectasia, corneal foreign body, lamellar corneal surgeries, assessment of architecture of corneal wounds or incisions, evaluation of intracorneal ring segments etc. Disciform keratitis is associated with herpes simplex and zoster group of viruses and involves endothelial dysfunction during viral and immune mediated endothelitis [1-6]. In patients with disciform keratitis, ASOCT can be an important adjunct in diagnosis, as well as monitoring response to treatment [7-10]. We present four cases of disciform keratitis that were followed up with serial ASOCT to monitor the response to therapy.

\section{Materials and Methods}

Four eyes of four patients with disciform keratitis were included in the case series. Diagnosis was made 


\section{Open Access Journal of Ophthalmology}

based on history and clinical findings on slit lamp biomicroscopy. ASOCT (Optovue Inc, California, and USA) was performed at the time of presentation, 2 weeks, one month and three months after starting the treatment to document corneal thickness, hyper reflectivity and corneal architecture at each visit.

\section{Case-1}

A 23-year-old male presented with complaints of blurring of vision, discomfort and watering in left eye for three days. The patient had a similar episode about six months ago in the same eye which resolved with treatment. The best corrected distance visual acuity on Snellen's acuity chart was 20/200. Slit lamp biomicroscopic examination revealed presence of central corneal edema predominantly involving stroma $(4 \times 4 \mathrm{~mm})$ with few fresh keratic precipitates and few pigments over the endothelium (Figure 1a). Corneal sensation as detected by response to touch by cotton wisp was reduced. Corneal epithelium was intact and there was no staining with fluorescein.

A clinical diagnosis of disciform keratitis was made. ASOCT was performed which revealed corneal thickness of $954 \mu$ in the maximally involved region with diffuse swelling in the posterior stroma. The patient was started on Tab Acyclovir 400mg five times a day, prednisolone acetate $1 \%$ eye drop four times a day, homatropine hydrobromide $2 \%$ eye drops twice daily and was asked to follow up. At two weeks, stromal swelling had markedly diminished with maximum corneal thickness reducing to $574 \mu$ with significant haze in posterior stroma (Figure 1b). Tab acyclovir and homatropine hydrobromide eye drops were stopped after two weeks. Prednisolone acetate $1 \%$ eye drop was continued twice daily for next two weeks and once daily for another two weeks and then it was stopped. At one month, there was complete resolution of stromal haze with corneal thickness reducing to $511 \mu$ on ASOCT (Figure 1c) and the distance visual acuity improved to $20 / 20$.

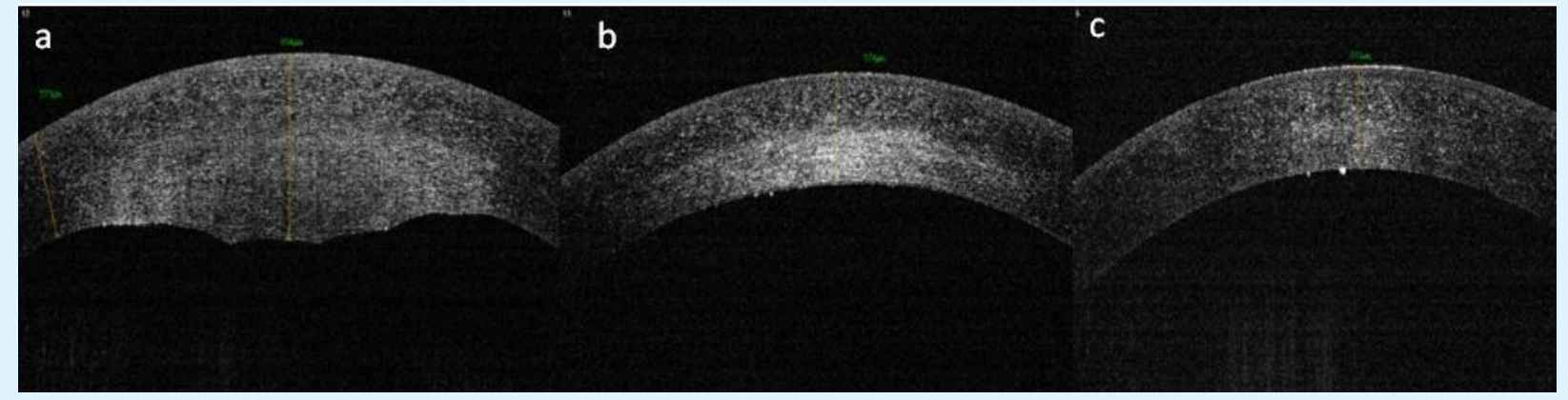

Figure 1: Case-1: ASOCT image of cornea of a patient with disciform keratitis

(a) Before starting treatment; (b) Two weeks after starting treatment; (c) One month after starting treatment

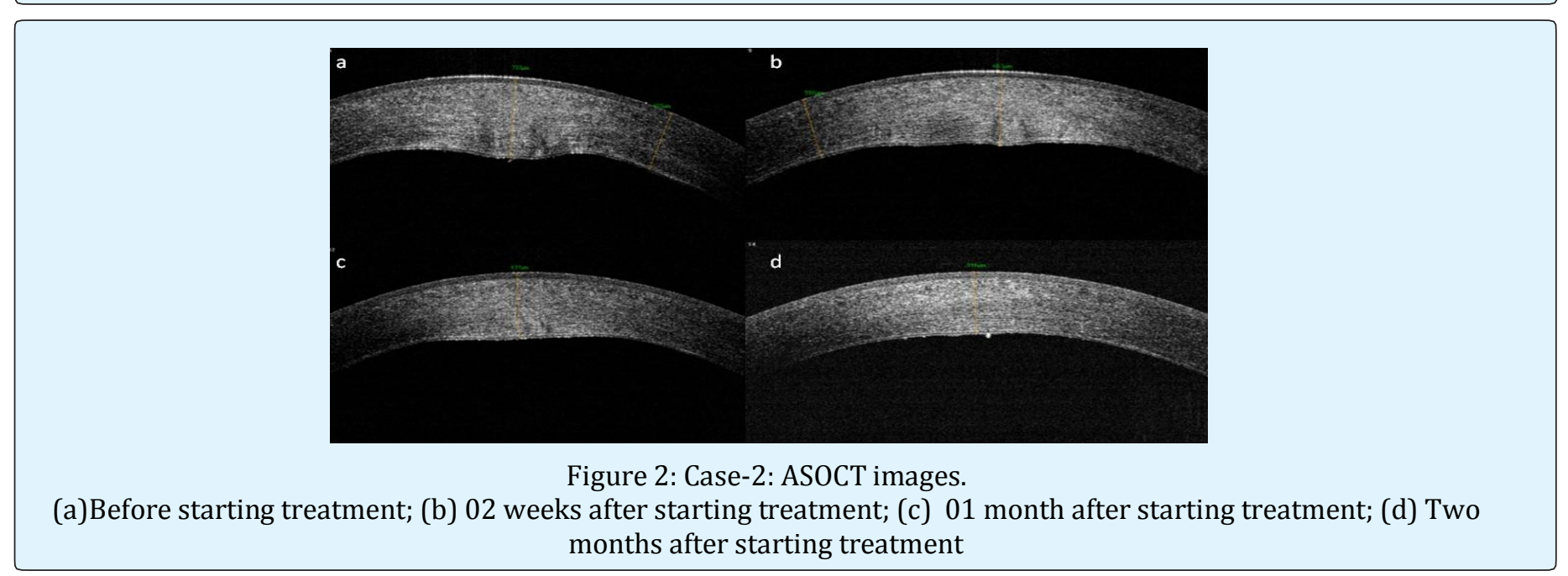

Vijay KS and Sagarika P. Anterior Segment Optical Coherence Tomography in Monitoring Therapeutic Response in Viral Disciform Keratitis. J Ophthalmol 2018, 3(4): 000161. 


\section{Open Access Journal of Ophthalmology}

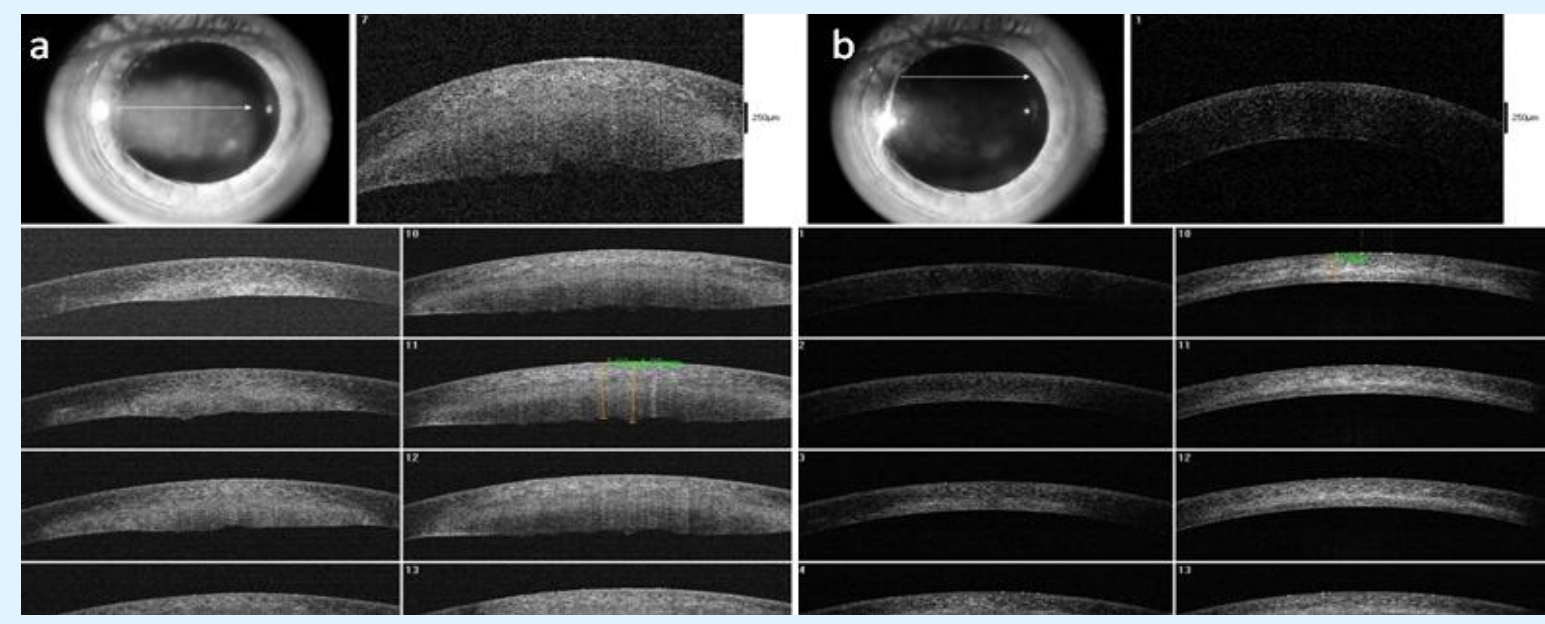

Figure 3: Case-3 ASOCT image.

(a) Before starting treatment; (b) 03 wks after starting treatment

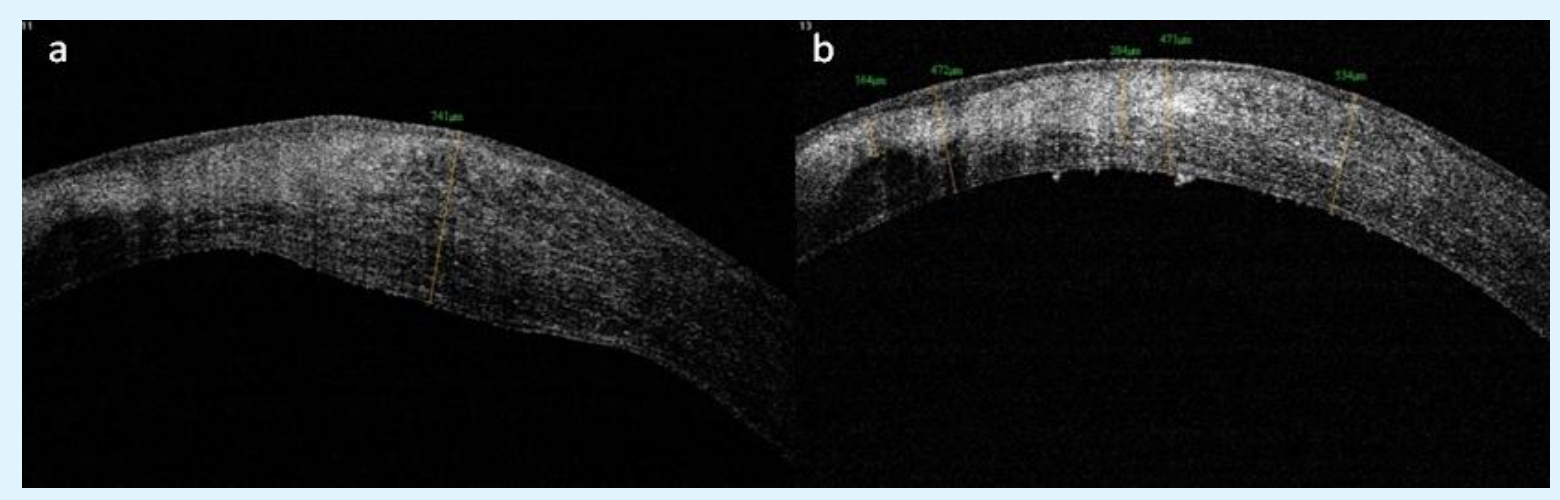

Figure 4: Case-4 ASOCT images.

(a) Before starting treatment; (b) 02 month after starting treatment

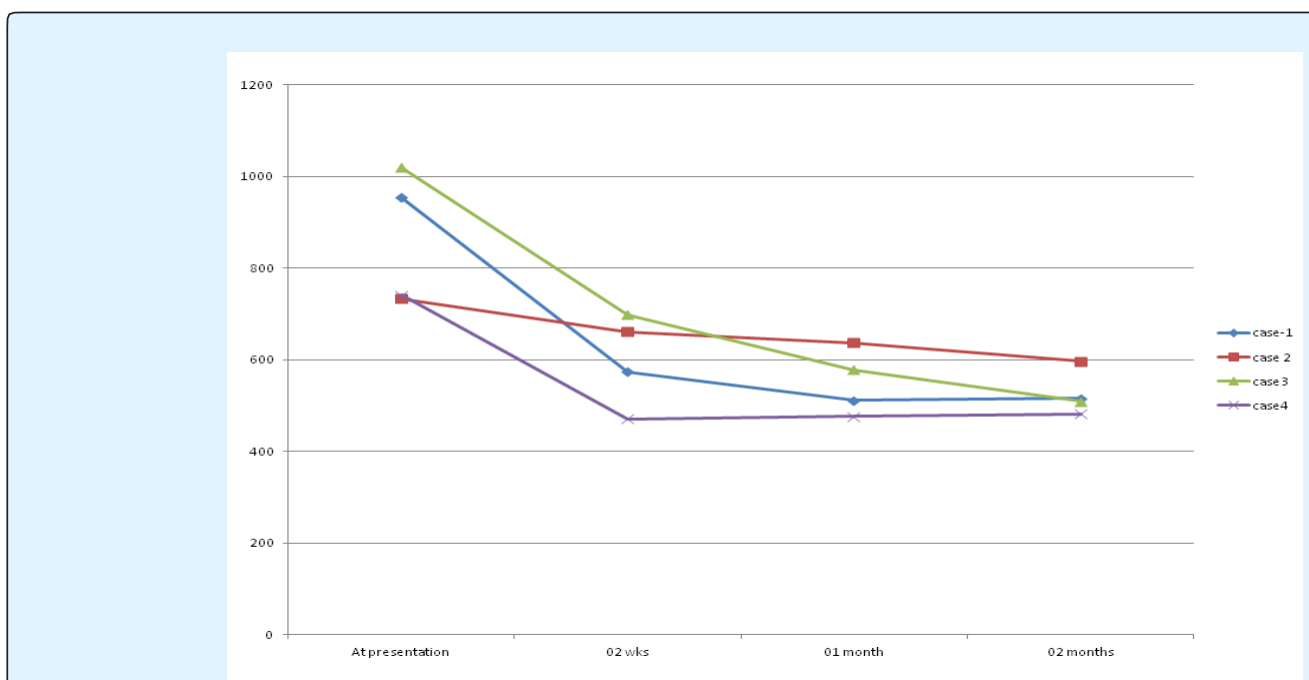

Figure 5: Chart demonstrating corneal thickness change for all patients over a period of two months. 


\section{Open Access Journal of Ophthalmology}

\begin{tabular}{|c|c|c|c|c|c|c|c|}
\hline $\begin{array}{c}\text { S. } \\
\text { No }\end{array}$ & $\begin{array}{c}\text { Age/ } \\
\text { Sex }\end{array}$ & $\begin{array}{c}\text { Initial } \\
\text { Visual } \\
\text { acuity }\end{array}$ & $\begin{array}{c}\text { ASOCT Corneal } \\
\text { thickness }(\boldsymbol{\mu}) \text { at } \\
\text { presentation }\end{array}$ & $\begin{array}{c}\text { ASOCT Corneal } \\
\text { thickness }(\boldsymbol{\mu}) \text { after 02 } \\
\text { weeks }\end{array}$ & $\begin{array}{c}\text { ASOCT Corneal } \\
\text { thickness }(\boldsymbol{\mu}) \text { after } \\
\mathbf{0 1} \text { month }\end{array}$ & $\begin{array}{c}\text { ASOCT Corneal } \\
\text { thickness }(\boldsymbol{\mu}) \text { after } \\
\text { 02 months }\end{array}$ & $\begin{array}{c}\text { Distance visual } \\
\text { acuity at } \mathbf{0 2} \\
\text { months }\end{array}$ \\
\hline 1 & $23 / \mathrm{M}$ & $20 / 200$ & 954 & 574 & 511 & 516 & $20 / 20$ \\
\hline 2 & $55 / \mathrm{F}$ & $20 / 400$ & 733 & 661 & 637 & 596 & $20 / 40$ \\
\hline 3 & $46 / \mathrm{M}$ & $20 / 1200$ & 1020 & 698 & 578 & 509 & $20 / 60$ \\
\hline 4 & $11 / \mathrm{M}$ & $20 / 400$ & 741 & 471 & 477 & 482 & $20 / 120$ \\
\hline
\end{tabular}

Table 1: Summary of patient data.

There were three more similar cases, the details of which have been mentioned in Table 1 and Figures 2-4.

On ASOCT, the corneal thickness showed maximum reduction in initial two weeks with resolution in stromal oedema and smoothening of posterior corneal contour (Figure 5). Hyper reflectivity on ASOCT showed initial increase after resolution of stromal oedema followed by decrease over next few weeks.

\section{Discussion}

Corneal imaging is improving with development of various newer modalities and ASOCT is one of such newer modality. It is being increasingly explored in evaluation and management of many corneal disorders. Konstantopoulos, et al. described the imaging capabilities of ASOCT in microbial keratitis. Wilhelmus, et al. studied corneal thickness changes using ultrasonic pachymetry in herpes simplex virus disciform keratitis and concluded that it provides an important surrogate measure for monitoring treatment of HSV disciform keratitis [11]. Pachymetry was done at the midpoint of inflamed area of disciform keratitis although this may necessarily not be the area with maximum corneal thickness in the lesion of disciform keratitis [12]. ASOCT is advantageous in being a non contact technique and can scan a large area of cornea for evaluation in one capture compared to pachymetry. The site of maximum thickness can be outlined and the same site can be serially evaluated to look for the response to treatment. We evaluated serial ASOCT in cases of disciform keratitis and made an attempt to define the changes in cornea on ASOCT and their clinical correlation.

Corneal thickness is the most consistently affected parameter in a case of disciform keratitis. It shows marked increase (reaching almost double the value) at the time of presentation. As the treatment is started, the visual acuity improves, slit lamp biomicroscopic examination shows reduction in corneal thickness. The corneal thickness also decreases proportionately on ASOCT examination. In our case series, the maximum reduction in corneal thickness was seen in initial two weeks. The stromal reflectivity on ASOCT was less during acute stages of corneal oedema (probably due to presence of fluid in stroma) but increased over next few weeks as the stromal swelling and corneal thickness decreased. This was probably due to damage to stromal architecture due to corneal oedema and inflammation and reflectivity increased as the stromal oedema (hence fluid) decreased manifesting clinically as various grades of corneal opacity. Although this hyper reflectivity also decreased over next couple of months as the patients were continued on tapering doses of steroid eye drops associated with improvement in visual acuity.

Oedema during acute stage was markedly seen in posterior cornea with presence of irregular bumpy posterior corneal surface. Anterior surface and anterior corneal curvature were well maintained during the entire episode of disciform keratitis in all our cases. Keratic precipitates and pigments were imaged more towards later part of the disease process on ASOCT presenting as hyper reflective dots over endothelium although keratic precipitate were present at the time of initial presentation on slit lamp biomicroscopic examination. ASOCT failed to pickup keratic precipitates early in the disease process. Although there were few patients included in our study but the characteristic serial ASOCT images over a period of two months have not been described earlier in the literature. These changes are quite characteristic and can be helpful in determining the therapeutic response in disciform keratitis.

ASOCT evaluation of cornea may provide an important surrogate objective measure for assessment of the disease and monitoring the response to treatment in cases of disciform keratitis. By ASOCT, one can ensure monitoring of the site of maximum thickness each time so that the response to treatment can be accurately assessed.

\section{References}

1. Konstantopoulos A, Hossain PH, Anderson DF (2007) Recent advances in ophthalmic anterior segment 


\section{Open Access Journal of Ophthalmology}

imaging: a new era for ophthalmic diagnosis?. Br J Ophthalmol 91(4): 551-557.

2. Calladine D, Packard R (2007) Clear corneal incision architecture in the immediate postoperative period evaluated using optical coherence tomography. J Cataract Refract Surg 33(8): 1429-1435.

3. Lai MM, Tang M, Andrade EM, Li Y, Khurana RN, et al. (2006) Optical coherence tomography to assess intrastromal corneal segment depth in keratoconic eyes. J Cataract Refract Surg 32(11): 1860-1865.

4. Memarzadeh F, Li Yan, Francis BA, Ronald E Smith, Julie Gutmark, et al. (2007) Optical coherence tomography of the anterior segment in secondary glaucoma with corneal opacity after penetrating keratoplasty. Br J Ophthalmol 91(2): 189-192.

5. Sarodia U, Sharkawi E, Hau S, Barton K (2007) Visualization of aqueous shunt position and patency using anterior segment optical tomography. Am J Ophthalmol 143(6): 1054-1056.

6. Lim LS, Aung HT, Aung T, Tan DT (2008) Corneal imaging with anterior segment optical coherence tomography for lamellar keratoplasty procedures. Am J Ophthalmol 145(1): 81-90.

7. O'Brien WJ, Palmer ML, Guy J, Taylor JL (1996) Endothelial barrier function and $\mathrm{Na}+/ \mathrm{K}+-\mathrm{ATPa} e$ pump density in herpetic stromal disease. Invest Ophthalmol Vis Sci 37(1): 29-36.

8. Holbach LM, Font RL, Naumann GO (1990) Herpes simplex stromal and endothelial keratitis. Granulomatous cell reactions at the level of Descemet's membrane, the stroma, and Bowman's layer. Ophthalmology 97(6): 722-728.

9. Zheng X, Yamaguchi M, Goto T, Okamoto S, Ohashi $Y$ (2000) Experimental corneal endotheliitis in rabbit. Invest Ophthalmol Vis Sci 41(2): 377-385.

10. Barron BA, Gee L, Hauck WW, Kurinij N, Dawson CR, et al. (1994) Herpetic EyeDisease Study. A controlled trial of oral acyclovir for herpes simplex stromal keratitis. Ophthalmology 101(12): 1871-1882.

11. Konstantopoulos A, Kuo J, Anderson D, Hossain P (2008) Assessment of the use of anterior segment optical coherence tomography in microbial keratitis. Am J Ophthalmol 146(4): 534-542.

12. Wilhelmus KR, Sugar J, Hyndiuk RA, Stulting RD (2004) Corneal thickness changes during herpes simplex virus disciform keratitis. Cornea 23(2): 154157.

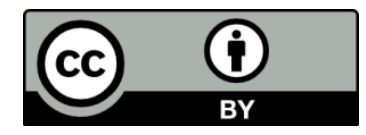

